years, any at risk gambling was associated with higher depression and anxiety scores, and wellbeing scores in the lowest quartile. The adjusted odds ratios (95\% CI) were highest in the moderate/problem group at 20yrs: depression 2.29 (1.28, 4.12), low wellbeing 1.61 (1.01, 2.57), involvement in crime $2.47(1.54,3.97)$, problematic use of alcohol $2.64(1.13,6.17)$, and drug use 1.79 (1.16, 2.75). Problem gamblers were more likely to have parents who gambled.

Conclusion Although many young people gamble without any harm, a significant minority (mainly males) show problem gambling behaviours which are associated with poor mental health, low wellbeing, and potentially harmful use of drugs and alcohol.

\section{A BIOPSYCHOSOCIAL MODEL OF CARE FOR CHILDREN AND YOUNG PEOPLE (CYP) WITH PERSISTENT, UNEXPLAINED, PHYSICAL SYMPTOMS (PUPS)}

1J Pales*, ${ }^{1} \mathrm{~K}$ Street, ${ }^{1} \mathrm{R}$ Howells, ${ }^{2} \mathrm{~A}$ Lee, ${ }^{2} \mathrm{~J}$ Burrows, ${ }^{3} \mathrm{~A}$ Boyd, ${ }^{3} \mathrm{~T}$ Bloomfield, ${ }^{4} \mathrm{~V}$ Palfrey. ${ }^{1}$ Paediatrics, Royal Devon and Exeter Foundation NHS Trust, Exeter, UK; ${ }^{2}$ Child and Adolescent Mental Health Service, Virgin Care Ltd, Exeter, UK; ${ }^{3}$ Psychology, Virgin Care Ltd, Exeter, UK; ${ }^{4}$ School Inclusion Team, Devon County Council, Exeter, UK

\subsection{6/bmjpo-2019-RCPCH-SAHM.8}

Aims PUPS are common, reported by $10-25 \%$ of CYP. ${ }^{1}$ Symptoms can lead to poor function, overuse of medical resource and reduced school attendance. Co-morbid mental health problems often go unrecognised. Longer term outcomes include adult chronic physical/mental ill-health, reduced employment, high health/welfare costs. ${ }^{2} 3$ We established a pilot multi professional assessment/support service to meet the needs of these CYP.

Methods Weekly multiprofessional meetings including paediatrician, psychiatrist, CAMHS worker, psychologist and education wellbeing advisor (EWA) to discuss cases referred by health professionals. Patient/parent consent given. Outcomes included holistic paediatric assessment, joint appointments (paediatrician and CAMHS worker/psychologist), advice and guidance (A\&G) to referrer such as signposting/facilitated referral to community services. Some were offered short-term therapeutic intervention with CAMHS worker/psychologist and/or psychiatric assessment. In all cases clear communication with school was facilitated by EWA who supported school attendance; assisting re-integration and improved attendance/ wellbeing at school.

Results Over 18 months we discussed 180 patients: 74 male, 104 female, 2 transgender. Average age 14 years. Common PUPS were musculoskeletal pain, fatigue, headaches, abdominal pain and unexplained episodes. All had reduced school attendance. 111 cases referred by Paediatricians/Allied Health professionals, 56 new GP referrals, 13 presented acutely. 106 were offered paediatric appointments. $>50 \%$ were discharged with recommendations/advice to primary care/education. $25 \mathrm{had}$ joint appointments. 38 were seen by psychiatrist/CAMHS worker/psychologist for assessment/therapeutic intervention. Remainder received A\&G and EWA support. Cost analysis demonstrated average savings of $£ 2600 /$ patient in secondary care. School attendance improved for the majority with reintegration plans and reduction in use of out of school provision with associated cost savings. Referrals to tertiary services for chronic pain/fatigue were reduced and joint working with these services was developed. Linked case examples show significant improvement.

Conclusion Multiprofessional assessment using a biopsychosocial approach to CYP with PUPS leads to better recognition of underlying mental illness, improved short-term functional outcomes, reduced medical costs and improved school attendance. The challenge is securing longer term funding

\section{REFERENCES}

1. Hinton D, Kirk S. Families' and Healthcare Professionals' perceptions of healthcare services for children and young people with medically unexplained symptoms: a narrative review of the literature. Health \& social care in the community 2016;24 (1):12-26.

2. Campo JV. Annual Research Review: Functional somatic symptoms and associated anxiety and depression - developmental psychopathology in pediatric practice. Journal of Child Psychology and Psychiatry 2012;53:575-592.

3. Bermingham SL, Cohen A, Hague J, Parsonage P. The cost of somatisation among the working-age population in England for the year 2008-2009. Mental Health in Family Medicine 2010;7:71-84.

\section{P1 $\quad$ SOCIO-CULTURAL PERSPECTIVES ON CONDOM USAGE INTENTIONS AND BEHAVIOURS AMONGST AFRICAN ADOLESCENT MIGRANTS IN SOUTH AFRICA}

${ }^{1}$ RR Titus*, ${ }^{2}$ LL John-Langba. 'Social Development, University of Cape Town, Cape Town, South Africa; ${ }^{2}$ School of Applied Human Science, University of Kwazulu-Natal, KwazuluNatal, South Africa

\subsection{6/bmjpo-2019-RCPCH-SAHM.9}

Background Adolescent health has become a critical issue in the HIV intervention discourse as this particular cohort has an increased vulnerability to HIV infection, however migrant youth has an additional vulnerability due to their migrant status. African adolescents and migrant status are key population cohorts within South Africa identified as increased risk of HIV infection, sexual transmitted infection and reproductive health problems. Although increased focus into migration patterns in the South African context, not much research focused on the adolescent health of migrants. The impact of socio-cultural perspectives on condom use intentions and behaviour on migrant youth, which translate to the effect that social and cultural dynamics have on decision making processors of young people with regard to their sexual health choices and risk patterns of HIV and reproductive health.

Objective We examined migrant adolescent experiences of condom use in South Africa and identified socio-cultural factors influencing the condom use intentions and behaviours of migrant youth.

Method This qualitative study employed purposive and snowballing sampling techniques to explore with migrant youth regarding their intentions and behaviour towards condom use within their social cultural contexts. The sample included 20 African descent adolescents from Sub-Saharan African, notably from Zimbabwe, Nigeria, Congo, Cameroon, Kenya and Malawi. The mean age was 23 years with a range between 20 years to 25 years.

Results Findings indicated that young migrants have a good understanding of the functions of condoms and the dual protection against pregnancy and sexually transmitted infections. However, the use of condoms, even freely available, is a contested issue as socio-cultural practices and influences have an impact on the intentions and behaviour towards condom use among young migrant adolescents. 